\title{
Infilled Reinforced Concrete Beams for Sustainable
}

\section{Construction}

\author{
Patel Rakesh $^{1}$, Dubey Sheo Kumar ${ }^{1}$ and Pathak Krishna Kant ${ }^{2}$ \\ 1. Department of Civil Engineering, Maulana Azad National Institute of Technology, Bhopal 462051, India \\ 2. Department of Civil and Environmental Engineering, National Institute of Technical Teachers' Training and Research, Bhopal \\ 462002, India
}

\begin{abstract}
This paper presents a study carried out on infilled reinforced concrete beams for sustainable construction. In reinforced concrete beams, less stressed concrete below neutral axis can be replaced by some light weight material to reduce the weight of the structure and also achieve the economy. The used infilled material is brick. Sustainability can be achieved by replacing the partially used concrete. By saving concrete, the authors save cement, which reduces the green house gases emissions. So it is considered as environment friendly. Since infilled beam acts like a layered member, there needs a theory to analyze it. Method of initial functions is used for the analysis of the infilled RC (reinforced concrete) beams. This method is successfully applied on infilled beam. Results show that physical conditions are verified for infilled beam.
\end{abstract}

Key words: Initial functions, infilled beams, brick masonry, displacements, stresses.

\section{Introduction}

Sustainability means meeting the needs of the present generation without compromising the ability of future generations to meet their needs. Sustainability can be achieved by reducing, reusing and recycling the waste. It also means moving towards green technologies and reduces emission of $\mathrm{CO}_{2}$. Production of cement is also one of the main causes of man-made carbon dioxide emissions. Reduction of greenhouse gases and environmental pollution is great concerned for all of us. So the authors have to reduce the use of cement from concrete structures to make concrete more sustainable and environment friendly. This can be done by replacing cement in concrete with larger amounts of supplementary cementing materials, or by replacing less stressed or unutilized concrete by other low cost and environment friendly materials like alternative

Corresponding author: Patel Rakesh, research scholar, research fields: the development of concepts and methodologies for the concrete beams, composite material and sustainable construction. E-mail: rakeshasct@gmail.com. aggregates, bricks etc..

The main concept of the sustainable construction is to save the natural resources for future generation, by conserving virgin materials and protecting the environment by reducing, re-using and recycling the waste and reducing $\mathrm{CO}_{2}$ emissions [1]. An attempt has been made to design and produce sustainable concrete by using micro silica. It is sustainable concrete because waste material was used to produce high strength, workability and durability [2].

These days' attempts are being made for sustainable construction work and economise the costly reinforced concrete work. Like concrete, brick masonry was also reinforced to make it ductile and enable it to resist tensile forces. Reinforced brick work may be designed either on the basis of linear elasticity or the limit state philosophy of ultimate load design. It also follows the assumptions of bending theory that the plane sections remains plane after bending and that the tensile strength of brick work may be neglected.

In RC (reinforced concrete) beams strength of 
concrete lying near the neutral axis is not fully utilized. The concrete just above the neutral axis less stressed where as the concrete below the neutral axis serves as a shear transmitting media. Partially utilized concrete of $\mathrm{RC}$ beam has bean replaced by bricks. In this way, the economy of reinforced brick beams and strength of RC beams are tried to be combined in brick filled beams. The bond between brick and concrete layers at the brick concrete interface should essentially be very good. It should be ensured that no slip will occur between the two layers.

Experimental work is carried on the brick filled reinforced concrete beams, with the view that the stresses in the beams are maximum at the top and bottom and zero at the neutral axis. So a cheap and light material can be used near the neutral zone for light weight and economy [3]. Behavior of brick infilled reinforced concrete beams under cyclic loading is find out experimentally and compared the results with the conventional reinforced concrete beam. It is observed that the load carrying capacity of an infilled beam was about $80 \%$ of the conventional reinforced concrete beams [4]. Experimental study of brick filled reinforced concrete beam is done and it is observed that saving of about $30 \%$ concrete is achieved [5]. The analytical and experimental investigations on infilled frames under static and lateral loads are conducted and suggested that the load carrying capacity and stiffness of the infill frame is more than the plain frame [6]. The experimental programme is conducted on the beams with light weight brick core with ferrocement form. It is observed that beams achieved higher ultimate load when welded wire mesh is used in ferrocement forms [7].

The experimental work was conducted to obtain a stress-strain curve for the masonry, and determines the splitting tensile strength of the bricks and Poisson's ratio of the masonry. It was observed that the average splitting tensile strength of brick masonry was found to be $6.8 \%$ of the average compressive strength of bricks [8].

Method of initial functions is an analytical method of elasticity theory. It can be used for layered members. The method makes it possible to obtain exact solutions of different types of problems, i.e., solutions without the use of hypotheses about the character of stress and strain. It is used for the analysis of beams under symmetric central loading and uniform loading. Results are obtained for different end conditions [9]. The method of initial functions is used for the analysis of free vibration of rectangular beams of arbitrary depth. And present the analysis for different values of Poisson's ratio [10]. MIF (method of initial functions) has been applied for deriving higher order theories for laminated composite thick rectangular plates [11]. Developed governing equations for composite laminated deep beams by using method of initial functions. The developed beam theory can be used for beam sections of small depth and large depth [12]. Applied MIF (method of initial functions) for the analysis of orthotropic deep beams and compared the results with the available theory based on Bernoulli's hypothesis [13].

\section{Brick Replacement Zone}

The replacement zone in reinforced concrete beam, where concrete below neutral axis may be replaced by bricks was obtained with the help of stress block, used for limit state design of RC beams. Fig. 1 shows the stress block parameters for RC beams.

By equating total tension to total compression,

$X_{u}=\left(0.87 f_{y} A_{s t}\right) /\left(0.36 f_{c k} b\right)$ as per IS 4562000 [14].

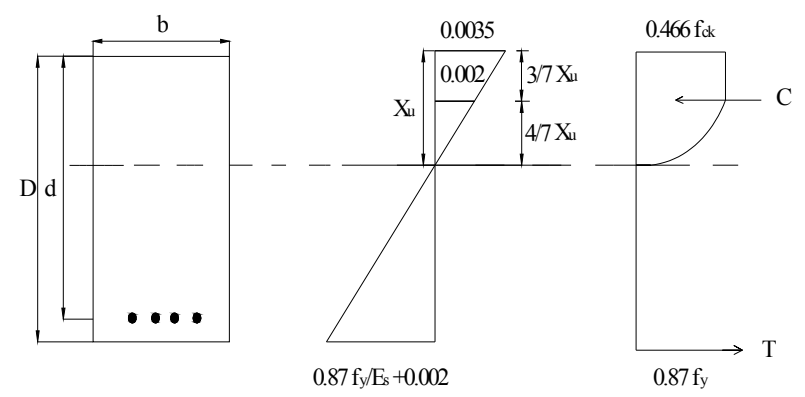

Fig. 1 Stress block parameters for RC beams. 
$d^{\prime}=(2 \times$ cover + diameter of bar $)$

$d$ ' is the thickness of concrete layer available to maintain bond between steel and concrete. It is assumed the provision of thickness of concrete not less than the cover provided on each side of the tension reinforcement will satisfy the bond requirement.

$$
d_{\text {min }}=3 X u / 7+X b
$$

Brick replacement zone $=d_{\max }-d_{\min }$

This brick replacement zone is shown in Fig. 2.

\section{Formulation Using MIF}

The brick filled reinforced concrete beams are analyzed by using MIF (method of initial functions). According to this method, the basic desired functions are the displacements and stresses, the system of differential equations which are obtained from equations of Hooke's law and equilibrium equations by replacing stresses by the displacements according to elasticity relations. The order of the derived equations depends on the stage at which the series representing the stresses and displacements are truncated.

In the case of a layered composite beam loaded at the top surface, the state of stresses and displacements at the free bottom surface of the beam is given by:

$$
\left\{S_{1}\right\}=\left[\begin{array}{llll}
u_{1}, & v_{1}, & 0, & 0
\end{array}\right]^{T}
$$

Let

$$
\left\{S_{T}\right\}=\left[\begin{array}{llll}
u_{T}, & v_{T}, & Y_{T}, & X_{T}
\end{array}\right]^{T}
$$

where, $u_{T}, v_{T}, Y_{T}$ and $X_{T}$ are the values of stresses and displacements at the top surface of the layered beam.

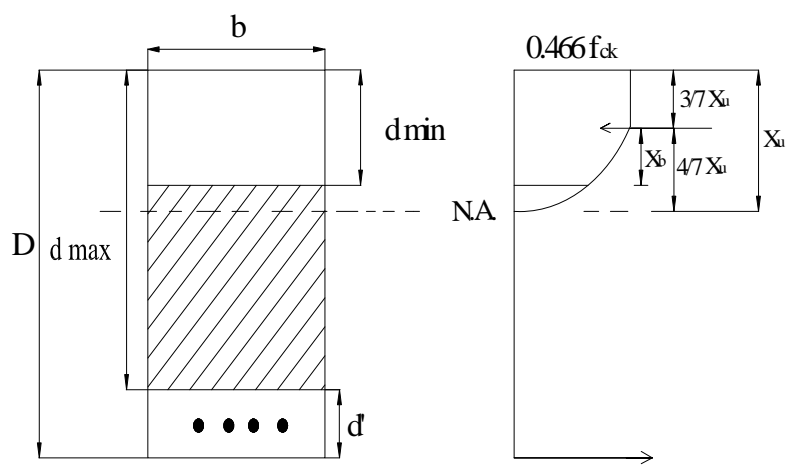

Fig. 2 Brick replacement zone in RC beams.
Relating the stresses and displacements at the top surface of the layer to those at the bottom surface by successive application of the transfer matrix $\left[L_{i}\right]$ across each layer, one obtains:

$$
\left\{S_{T}\right\}=[A]\left[S_{1}\right]
$$

where,

$$
[A]=\left[L_{N}\right]_{y_{N}=h_{N}} \ldots \ldots . .\left[L_{2}\right]_{y_{2}=h_{2}} \cdot\left[L_{1}\right]_{y_{1}=h_{1}}
$$

The terms of the matrix $[A]$ are evaluated after expanding the exponential in the form of a series.

The matrix has a form:

$$
[A]=\left[\begin{array}{llll}
A_{u u} & A_{u v} & A_{u Y} & A_{u X} \\
A_{v u} & A_{v v} & A_{v Y} & A_{v X} \\
A_{Y u} & A_{Y v} & A_{Y Y} & A_{Y X} \\
A_{X u} & A_{X v} & A_{X Y} & A_{X X}
\end{array}\right]
$$

The Eq. (3) relates the boundary conditions at the top surface to those at the bottom surface and is useful for deriving governing differential equations for a layered beam having a particular number of layers.

The method adopted for analyzing layered beams involves the determination of initial functions at the bottom surface of the beam by relating them through the matrix $[A]$ to the stresses at the top surface.

\section{Application to the Infilled Beam}

Brick filled reinforced concrete beam consists of the three layers as shown in Fig. 3. Top and bottom layers are of concrete and middle one is of brick. The area of reinforcement below the brick replacement zone is also converted in the equivalent area of concrete by using modular ratio.

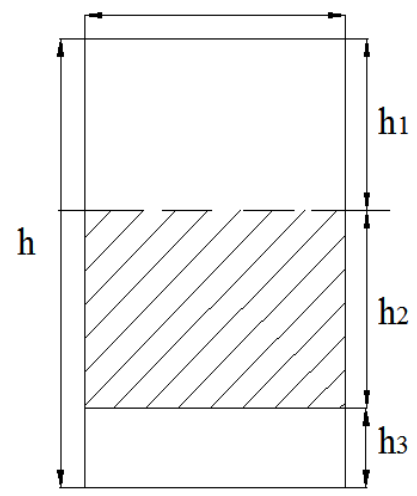

Fig. 3 Brick filled RC composite beam. 
Therefore, the matrix $[A]$ becomes

$$
[A]=\left[L_{1}\right]_{y_{1}=h_{1}} \cdot\left[L_{2}\right]_{y_{2}=h_{2}} \cdot\left[L_{1}\right]_{y_{3}=h_{3}}
$$

where, $h_{1}, h_{2}$ and $h_{3}$ are the thickness of three layers, $h_{1}$ and $h_{3}$ are the thickness of concrete layers, and $h_{2}$ is the thickness of brick layer.

The conditions at top are given by:

$$
\left\{S_{T}\right\}=\left[u_{T}, \quad v_{T}, \quad-p, \quad 0\right]^{T}
$$

Substituting the expressions (1) and (5) in the Eq. (3), it can be got:

$$
\begin{gathered}
A_{X u} u_{1}+A_{X v} v_{1}=0 \\
A_{Y u} u_{1}+A_{Y v} v_{1}=-p
\end{gathered}
$$

These equations are exactly satisfied by:

$$
\begin{gathered}
u_{1}=A_{X v} \phi \\
v_{1}=-A_{X u} \phi
\end{gathered}
$$

where, $\phi$ is an unknown auxiliary function substituting the value of $u_{1}$ and $v_{1}$ from the Eqs. (10) and (11) in the Eq. (9), the differential equation governing the problem of brick filled reinforced concrete beam is obtained:

$$
\left(A_{Y u} \cdot A_{X v}\right)-\left(A_{Y v} \cdot A_{X u}\right) \phi=-p
$$

The order of the governing differential Eq. (12) depends on the order of the terms in the matrix $[A]$.

The auxiliary function $\phi$ is chosen such that it satisfies the governing differential Eq. (12), as well as the boundary conditions at the edges of the beam. Initial functions are obtained from Eqs. (10) and (11). By operating on the initial functions by the transfer matrix $\left[L_{i}\right]$ successively across each layer, the authors can determine the stresses and displacements, within the entire beam.

\section{Analysis of Brick Filled Beam}

The following values of beam dimensions are chosen for the particular problem. The replacement zone is calculated using above relations and thickness of three layers are decided. Reinforced concrete brick filled composite beam consists of the three layers as shown in Fig. 3. Where, $h_{1}, h_{2}$ and $h_{3}$ are the thickness of three layers, $H$ is the total thickness and $b$ is the width of beam section. $h_{1}$ and $h_{3}$ are the thickness of concrete layers and $h_{2}$ is the thickness of brick layer.

$$
\begin{aligned}
& H=800 \mathrm{~mm}, b=300 \mathrm{~mm} \text { and } l=4,000 \mathrm{~mm} ; \\
& h_{1}=210 \mathrm{~mm}, h_{2}=510 \mathrm{~mm} \text { and } h_{3}=80 \mathrm{~mm} .
\end{aligned}
$$

The following material properties are taken:

For concrete layers:

$E=22,000 \mathrm{~N} / \mathrm{mm}^{2}$

$\mu=0.15, G=9,200 \mathrm{~N} / \mathrm{mm}^{2}$

For brick layer:

$E=5,000 \mathrm{~N} / \mathrm{mm}^{2}$

$\mu=0.10, G=2,200 \mathrm{~N} / \mathrm{mm}^{2}$

A uniformly distributed load is assumed, on the top surface of the beam:

Taking $P=25 \mathrm{~N} / \mathrm{mm}$.

The boundary conditions of the simply supported edges are:

$X=Y=v=0$, at $x=0$ and $x=l$

The boundary conditions are exactly satisfied by the auxiliary function $\phi$.

$$
\phi=\mathrm{A}_{1} \sin (\pi x / l)
$$

Analysis is done for $x=l / 2$ (mid span of beam)

\section{Results and Discussion}

The value of auxiliary function $\phi$ is obtained from Eq. (12), using this value of auxiliary function the values of initial functions $u_{1}$ and $v_{1}$ are obtained from Eqs. (10) and (11).

These values of $u_{1}$ and $v_{1}$ are substituted in Eq. (3) for obtaining the values of stresses and displacements. These values are shown in Table 1 .

From Fig. 4, it is observed that the value of displacement " $u$ " is more at the top surface and less at the bottom surface.

It can be seen from Fig. 5 that displacement " $v$ " is almost uniform throughout the depth.

From Fig. 6, it is observed that the value of normal stress $(Y)$ is zero at the bottom and maximum at the top of beam. The physical condition of normal stress equal to the applied normal load at the top fiber is satisfied. This figure is drawn to verify the physical condition of beam. It is seen from Fig. 7 that the shear 
Table 1 Values of stress and displacements at different depths of brick filled beam.

\begin{tabular}{llllll}
\hline S. No. & $\mathrm{y} / \mathrm{H}$ & $\mathrm{u} / \mathrm{H}$ & $\mathrm{v} / \mathrm{H}$ & $\mathrm{Y} / \mathrm{P}$ & $\mathrm{X} / \mathrm{P}$ \\
\hline 1 & 0.0 & 0.0594 & 0.1948 & 0.0000 & 0.0000 \\
2 & 0.1 & 0.0474 & 0.1953 & 0.0456 & 1.7835 \\
3 & 0.2 & 0.0373 & 0.1956 & 0.1419 & 2.1064 \\
4 & 0.3 & 0.0275 & 0.1960 & 0.2521 & 2.3531 \\
5 & 0.4 & 0.0180 & 0.1963 & 0.3724 & 2.5265 \\
6 & 0.5 & 0.0085 & 0.1967 & 0.4989 & 2.6294 \\
7 & 0.6 & -0.0008 & 0.1971 & 0.6277 & 2.6646 \\
8 & 0.7 & -0.0102 & 0.1976 & 0.7548 & 2.6349 \\
9 & 0.8 & -0.0211 & 0.1977 & 0.8763 & 2.2355 \\
10 & 0.9 & -0.0331 & 0.1976 & 0.9657 & 1.3180 \\
11 & 1.0 & -0.0453 & 0.1974 & 1.0002 & 0.0010 \\
\hline
\end{tabular}

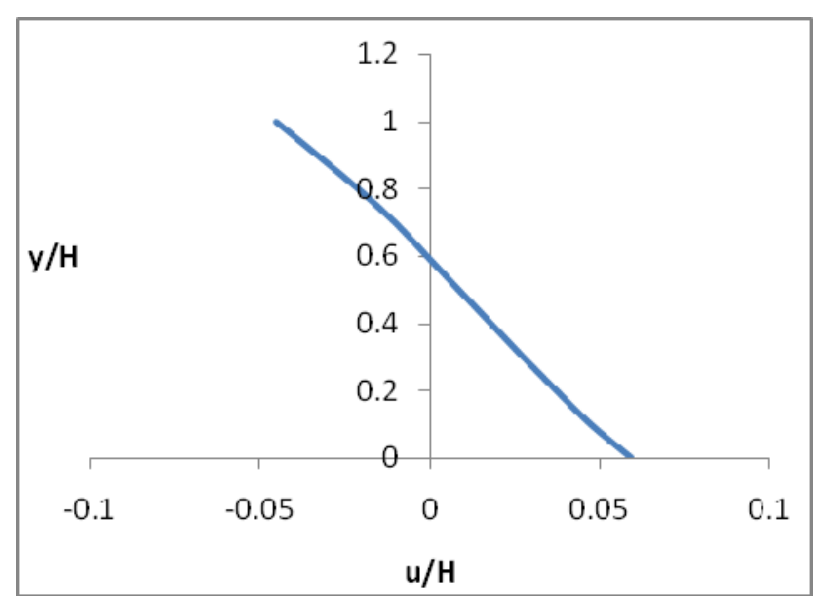

Fig. 4 Variation of $u$ through the depth of beam.

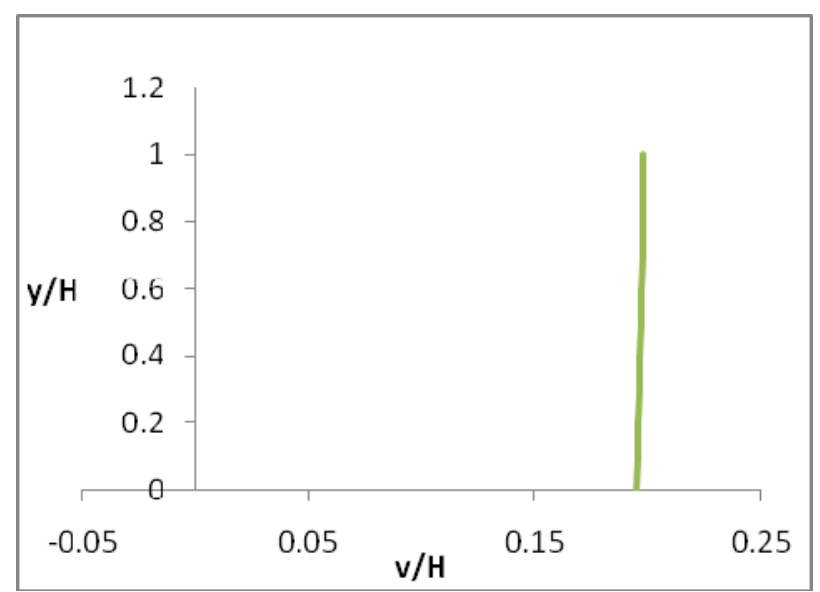

Fig. 5 Variation of $v$ through the depth of beam.

stress $(X)$ is maximum below the mid depth. It is calculated at the mid of beam.

From this method results are obtained in terms of two displacements $u, v$ and stress components $Y, X$.

These terms for infilled $\mathrm{RC}$ beam are shown from

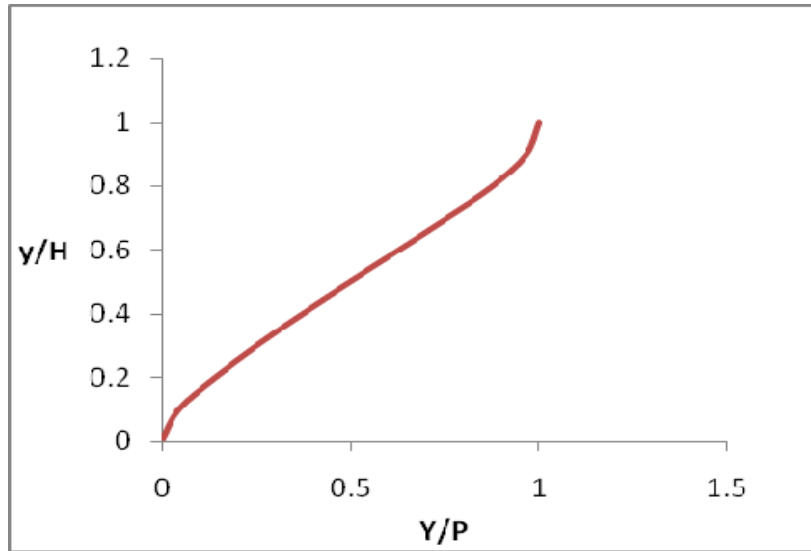

Fig. 6 Variation of normal stress $(Y)$ through the depth of beam.

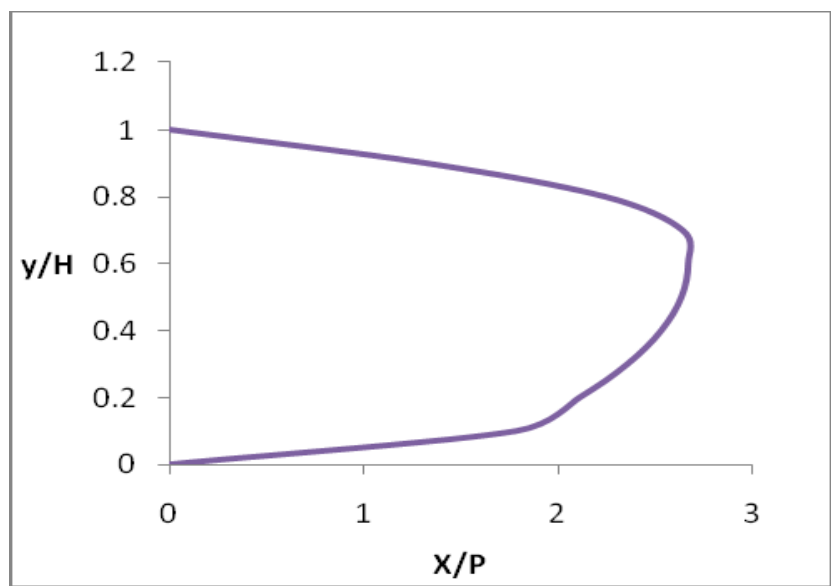

Fig. 7 Variation of shear stress $(X)$ through the depth of beam.

Fig. 4 to Fig. 7. This theory gives better results for layered members in comparison to elementary beam theory. The eighth order MIF theory is used for analysis.

\section{Conclusions}

The normal stress equal to the intensity of loading and shear stress equal to zero at the top of beam are obtain, this shows that MIF is successfully applied for the analysis of infilled beams. The beam theories based on MIF have advantage over other theories because of their capabilities to converge to an exact linear elasticity solution and so provide a governing equation of desired order according to the requirements of a beam problem.

Presence of bricks in the low stressed zone has not 
caused significant reduction in strength of reinforced concrete beams.

Economy and reduction of weight in beams depends on the percentage replacement of concrete by bricks. Brick-filled reinforced concrete beams can be used for sustainable and environment friendly construction work as it saves concrete.

\section{References}

[1] J.P. Desai, New trends in green technologies for sustainable construction, in: Proceedings of International Seminar on Green Technologies for Sustainable Concrete Construction, New Delhi, 2012.

[2] A.K. Al-Tamimi, N. Iqbal, Design and production of sustainable structural concrete, in: Proceedings of International Seminar on Green Technologies for Sustainable Concrete Construction, New Delhi, 2012.

[3] P. Govindan, A.R. Santhakumar, Composite action of reinforced cement concrete beams with plain masonry infills, in: Proceedings of International Symposium on Reinforced and Pre-stressed Masonry, Edinburgh, 1984.

[4] P. Govindan, M. Lakshmipathy, A.R. Santhakumar, Behaviour of infilled beams under cyclic loading, Indian Concrete Journal 61 (5) (1987) 124-128.

[5] U.B. Choubey, U. Gupta, Structural response of brick-filled reinforced concrete beams, in: Proceedings of 4th International Seminar on Structural Masonry for Developing Countries, Madras, 1992, pp. 226-233.
[6] S. Arulselvan, K. Subramanian, P.E.B. Pillai, A.R. Santhakumar, RC Infilled frame-RC plane frame interactions for seismic resistance, Journal of Applied sciences 7 (7) (2007) 942-959.

[7] H.F. Ezzat, N.A. Mohamed, B.S. Yousry, A.A. Ahmed, Permanent ferrocement forms: A viable alternative for construction of concrete beams, in: 30th Conference on Our World in Concrete \& Structures, Singapore, 2005.

[8] M. Gupta, A.K. Pandey, Experimental studies on brick masonry in compression, Indian Concrete Journal 86 (1) (2012) 43-50.

[9] K.T.S. Iyengar, K. Chandrashekhara, V.K. Sebastian, Thick rectangular beams, Journal of the Engineering Mechanics Division 100 (6) (1974) 1277-1282.

[10] K. Iyengar, T.S. Raja, P.V. Raman, Free vibration of rectangular beams of arbitrary depth, Acta Mechanica 32 (1) (1979) 249-259.

[11] K.T.S. Iyengar, S.K. Pandya, Application of the method of initial functions for the analysis of composite laminated plates, Archive of Applied Mechanics 56 (6) (1986) 407-416.

[12] S.K. Dubey, Analysis of composite laminated deep beams, in: Proceedings of the Third International Conference on "Advances in Composites", Bangalore, 2000, pp. 30-39.

[13] S.K. Dubey, Analysis of homogeneous orthotropic deep beams, Journal of Structural Engineering 32 (2) (2005) 109-166.

[14] Plain and Reinforced Concrete-Code of Practice, IS: 456-2000, Indian Standard, 2000. 